\title{
Sapientia et vera amicitia: César Lorenzo Raña Dafonte (1940-2018) \\ y la filosofía del Renacimiento del siglo XII
}

\section{Cuando ya todo se ha hecho historia}

Lo que bien traducía César Lorenzo Raña Dafonte hacia el final del Entético Mayor ${ }^{1}$ [Entheticus de dogmate philosophorum] (ca.1157) de Juan de Salisbury (1110-1180): «A todo autor se le deben por un deber perenne, agradecimiento, veneración, amor sumiso», este año, en recuerdo y memoria, se ha tornado en obligado cumplimiento y reconocimiento hacia su persona y su obra en esta Revista Española de Filosofía Medieval, cuando César fallecía el 17 de noviembre de este 2018 en Santiago de Compostela y ya todo se ha hecho historia. En su memoria pretenden estas líneas, desde el agradecimiento compartido, evocar y efectuar una aproximación a este gran autor de fecunda obra, que enseñando y deleitando se hizo querer, y que con arte admirable ha sabido atraer y abrir muchos caminos fructíferos a la Filosofía Medieval.

Sobre César y con motivo de su jubilación, su colega y amigo el Profesor Martín González Fernández en la Universidad de Santiago de Compostela supo efectuar ya, antes de las sentidas palabras dadas también en este volumen, una magnífica y completa semblanza ${ }^{2}$, llegando hasta esa fecha de 2010 en que César fue nombrado profesor ad honorem de su dicha Universidad. Ahora, teniendo delante y en muchos casos sintiéndome deudor de dicha presentación, se pretende efectuar una aproximación a algunas de las claves y temas que están presentes en su rica obra y pensamiento ${ }^{3}$. Se halla dividida esta exposición en dos partes principales. En la primera parte se señalan los intereses primeros filosóficos que estuvieron presentes en César L. y que luego se fueron ampliando y variando hasta llegar y concretarse en la filosofía medieval. En la segunda parte se muestra como su dedicación a la filosofía medieval se fue concretando en la filosofía del Renacimiento del siglo XII, hasta convertirse en uno de los impulsores y divulgadores más significativos de la misma. En este sentido, en esta segunda parte, se efectúa un acercamiento a los temas y autores que César más supo atender y cuidar a través de sus publicaciones. Y se concluye con una mirada agradecida a su tarea como autor relevante dentro de la Filosofía Medieval y miembro de la Sociedad de Filosofía Medieval (SOFIME).

1 Raña Dafonte, C.L., «Juan de Salisbury (1110-1180): Entético sobre la doctrina de los filósofos (3 ${ }^{\mathrm{a}}$ parte)», Revista Española de Filosofia Medieval, 23 (2016), pp. 369, § 1843-44. Otro distinto es el Entético Menor, que sirve de Prólogo al Policraticus (1159).

2 González Fernández, M., «César L. Raña Dafonte, medievalista», Revista Española de Filosofia Medieval, 18 (2011), pp. 243-247, y en la página web de la misma:

https://www.uco.es/ucopress/ojs/index.php/refime/article/view/6135/5750.

3 Ésta es accesible en gran parte, a fecha de este 2018, a través de la página web de la Revista Española de Filosofia Medieval, https://www.uco.es/ucopress/ojs/index.php/refime/issue/archive, y base de datos Dialnet: Revista Española de Filosofia Medieval, https:/dialnet.unirioja.es/servlet/revista?codigo=1225, así como en la misma Dialnet: César Lorenzo Raña Dafonte, https:/dialnet.unirioja.es/servlet/autor?codigo=169913, en donde se recogen 30 artículos de revistas, 20 colaboraciones en obras colectivas, 2 en libros, 1 Tesis Doctoral y la coordinación de la publicación de un libro. 


\section{De Amor Ruibal (1869-1930) a la filosofía medieval: Simposio sobre la filosofía y ciencia en el Renacimiento (Santiago de Compostela, 31-10 al 02-11/1985)}

Conocí a César L. Raña en el Simposio sobre Filosofía y Ciencia en el Renacimiento 4 que se celebraba en la Universidad de Santiago de Compostela, durante los días del 31 de octubre al 2 de noviembre de 1985, organizado por el Departamento de Filosofía e Antropoloxía Social y dirigido por el Prof. Dr. Carlos Baliñas Fernández. Era la primera vez que en España acontecía un evento de estas características dedicado a la filosofía y ciencia en el Renacimiento. Desde otros campos del saber y perspectivas, sin embargo, ya se sucedían. Era el caso de la Academia Literaria Renacentista en la Universidad de Salamanca ${ }^{5}$ que desde el año 1975 celebraba sus encuentros. Eran los que desde el año 1958 la Société Internationale pour l'Étude de la Philosophie Médiévale (S.I.E.P.M.) impulsaba a través de sus Congresos internacionales y en los cuales se consolidaba una nueva mirada sobre el Renacimiento y sobre lo que había significado la filosofía y el mundo medieval ${ }^{6}$. Impulso que hasta estas fechas había estado llegando a España a través, entre otros, de Salvador Gómez Nogales, Joaquín Lomba Fuentes, José Antonio García-Junceda, Laureano Robles y Vicente Muñoz Delgado, y los que empezaba a abrir Rafael Ramón Guerrero. Y eran los Seminarios de Historia de la Filosofía Española,

4 Las Actas de este Simposio fueron publicadas bajo el título, Filosofia y Ciencia en el Renacimiento, Servicio de Publicaciones e Intercambio Científico de la Universidad de Santiago de Compostela, 1988, 394 pp. Los títulos de los distintos trabajos aparecen en Dialnet: Filosofia y Ciencia en el Renacimiento: actas del Simposio celebrado en Santiago de Compostela, del 31 de octubre al 2 de noviembre de 1985, https:/dialnet.unirioja.es/ servlet/libro?codigo $=1112$.

5 Cf. Sus publicaciones tal como quedan recogidas en Dialnet: Academia Literaria Renacentista, https://dial net.unirioja.es/congreso/265, y dedicadas, entre otros autores, a Fray Luis de León (1979), Nebrija y la introducción del Renacimiento en España (1981) y a Garcilaso (1983).

6 Hasta esta fecha de 1985 habían sido los siguientes:

1. L'homme et son destin d'après les penseurs du moyen âge. Actes du premier congrès international de philosophie médiévale, Louvain-Bruxelles, 28 août - 4 septembre 1958. Louvain, Éditions Nauwelaerts - Paris, BéatriceNauwelaerts, 1960, 845 pp.

2. Die Metaphysik im Mittelalter, ihr Ursprung und ihre Bedeutung. Vorträge des II. internationalen Kongresses für mittelalterliche Philosophie, Köln 31. August - 6. September 1961. Im Auftrage der Société internationale pour l'étude de la philosophie médiévale (S.I.E.P.M.), herausgegeben von P. Wilpert, unter Mitarbeit von W.P. Eckert (Miscellanea Mediaevalia, 2). Berlin, Walter de Gruyter \& Co., 1963, XXII-795 pp.

3. La filosofia della natura nel Medioevo. Atti del terzo congresso internazionale di filosofia medioevale, Passo della Mendola (Trento), 31 agosto - 5 settembre 1964. Milano, Società editrice Vita e pensiero, 1966, XX-808 pp.

4. Arts libéraux et philosophie au moyen âge. Actes du quatrième congrès international de philosophie médiévale, Université de Montréal, Canada, 27 août - 2 septembre 1967. Montréal, Institut d'Études Médiévales, Paris, Librairie philosophique J. Vrin, 1969, XXIV-1249 pp.

5. Actas del V Congreso internacional de filosofia medieval. Madrid, Editora Nacional, 1979, vol. I, 697 pp.; vol. II, 707-1409 pp. (Madrid, Córdoba, Granada, 5 - 12 septembre 1972, Encuentro de culturas en la filosofia medieval).

6. Sprache und Erkenntnis im Mittelalter. Akten des VI. internationalen Kongresses für mittelalterliche Philosophie der Société internationale pour l'étude de la philosophie médiévale, 29. August - 3. September 1977 in Bonn, herausgegeben von J.P. Beckmann, L. Honnefelder, G. Jüssen, B. Münxelhaus, G. Schrimpf, G. Wieland unter Leitung von W. Kluxen (Miscellanea Mediaevalia, 13/1 et 13/2). Berlin - New York, Walter de Gruyter, 1981, XXIV-546 et XII, 547-1113 pp.

7. L'homme et son univers au moyen âge. Actes du septième congrès international de philosophie médiévale (30 août - 4 septembre 1982), édités par Ch. Wenin (Philosophes médiévaux, XXVI et XXVII). Louvain-la-Neuve, Éditions de l'Institut supérieur de philosophie, 1986, XIV-479 et 481-961 pp. 
que organizados por Antonio Heredia Soriano desde la Universidad de Salamanca a partir de 1978 sabían acercarse con una nueva serenidad metodológica a la Filosofía española y a la Historia de la Filosofía en todas sus épocas y autores ${ }^{7}$.

Y era en torno a estas fechas 1985 el inicio de un tiempo nuevo y perspectiva en el hacer filosófico que comenzaba a vivirse y a sentirse, y que llegaba a las aulas, congresos, Tesis doctorales... y a la misma promoción del propio profesorado universitario. La filosofía era valiosa si en sí misma, en acreditada investigación, era filosofía, y así era reconocida, al igual que los muchos jóvenes filósofos que en todos los ámbitos también así lo eran. Y eso fue lo que significaba el Simposio de Santiago y lo que quedó expresado en sus distintas Secciones y ponencias ${ }^{8}$.

Era una filosofía viva, plural, rica, donde todos los autores y temáticas, en afán de aprender y perfeccionar, eran bien recibidas, pero era una filosofía exigente en su metodología que obligaba a repensar las tradiciones filosóficas y a efectuar interpretaciones y acercamientos más contrastados y completos. Dichas Secciones fueron las siguientes: I. Recepción y restauración de las filosofías antiguas. II. Escepticismo y corrientes críticas. III. Ciencia, magia, alquimia, cabbala. IV Vivencia y teoría del amor (del amor cortés al amor platónico). V. Entre la razón de estado y la utopía. VI. Simbolismo, mitología, iconología. VII y VIII. Lenguaje, filología, crítica a la lógica medieval.

Sería en esta última Sección donde César expondría su ponencia titulada, El humanismo del siglo XII y su proyección en el humanismo ${ }^{9}$, y donde se proponía «tratar de poner de manifiesto ciertos gérmenes del humanismo renacentista en la Edad Media y, más concretamente, en el siglo XII $\gg{ }^{10}$ para centrar su exposición con atención admirada en Juan de Salisbury ${ }^{11}$ y su humanismo en el siglo XII. Este acercamiento iba a marcar el giro y la inflexión que en César L. Raña se estaba produciendo hacia la filosofía medieval, en concreto a la del siglo XII y a algunos de sus autores más significativos: Bernardo de Chartes (ca. 1124-1130), Pedro Abelardo (1079-1142), Hugo de San Víctor (1097?-1141), Juan de Salisbury (1110-1180) y Alano de Lille (114/1129-1203). Apertura y dedicación que, sin embargo, no iba a olvidar sus primeras investigaciones e inquietudes filosóficas a través de Ángel Amor Ruibal (1869-

7 La edición ininterrumpida de las Actas de los distintos Seminarios llegan desde el año 1978 hasta 2002 (Heredia, A., R. Albares y R. Piñero (Eds.), Filosofia hispánica contemporánea: el 98. Actas del XI Seminario de Historia de la Filosofia Española e Iberoamericana, Universidad de Salamanca, Facultad de Filosofia, 21 al 25 de septiembre de 1998, Fundación Gustavo Bueno, 2002, 632 pp. Y la referencia de dichas primeras actas es la siguiente: Heredia Soriano, A. (ed.), Actas del I Seminario de Historia de la Filosofia Española. Salamanca, del 27 de abril al 1 de mayo de 1978, Ediciones Universidad de Salamanca, 1978; Id., Actas del II Seminario de Historia de la Filosofia Española, Salamanca, del 28 de abril al 2 de mayo de 1980, Ediciones Universidad de Salamanca, 1982, 2 vols.; Id., Actas del III Seminario de Historia de la Filosofia Española, Salamanca, del 27 de septiembre al 1 de octubre de 1982, Ediciones Universidad de Salamanca, 1983; Id., Actas del IV Seminario de Historia de la Filosofia Española, Salamanca, del 24 al 28 de septiembre de 1984, Ediciones Universidad de Salamanca, 1986; Id., Actas del V Seminario de Historia de la Filosofia Española, Salamanca, del 22 al 26 de septiembre de 1986, Ediciones Universidad de Salamanca, 1988. El contenido de cada una de dichas Actas puede ser consultado en la base de datos Dialnet.

8 Los títulos de las distintas ponencias, tal como se indicó anteriormente, pueden ser consultados en Dialnet: Filosofía y Ciencia en el Renacimiento.

9 Actas, Filosofia y Ciencia en el Renacimiento, pp. 357-362.

$10 \quad$ Ibidem, p. 357.

11 Ibid., pp. 360-362. 
1930), y la influencia que en su formación recibiera de Vicente Muñoz Delgado (1922-1995). De modo admirable la revisión y actualización que Amor Ruibal había hecho de la filosofía, marcando sus insuficiencias, llevaban ahora a César, desde esta coyuntura nueva que se estaba viviendo en torno a esta década de 1980, a volver a la filosofía medieval para suplirlas y retomar lo mejor de ella en un intento de así mejor repensar y construir el actual presente.

En este sentido, cabe recordar su Tesis doctoral, Concepción de la divinidad en el pensamiento de Amor Ruibal (1977) defendida en la Facultad de Filosofía y Ciencias de la Educación de la Universidad de Santiago de Compostela y dirigida por Carlos Amable Baliñas Fernández, y sus primeras publicaciones: «La analogía según Ángel Amor Ruibal» ${ }^{12}$ (1981); «Datos para una teodicea según Amor Ruibal» ${ }^{13}$ (1985); «Un texto de Ángel Amor Ruibal» ${ }^{14}$ (1990); «Influencias filosóficas en la idea de Dios de los primeros teólogos cristianos, según Amor Ruibal» ${ }^{15}$ (1985). Así como las que luego aparecerían: «Análisis histórico-crítico del argumento anselmiano según Ángel Amor Ruibal» ${ }^{16}$ (1995); «Vicente Muñoz Delgado y Ángel Amor Ruibal» ${ }^{17}$ (1997).

Este haber llegado, encontrar y encontrarse en la filosofía medieval, con la posibilidad de dedicarse plenamente a ella con verdadero gozo y hacerla así compartida, bonum est diffusivum sui, se vio culminado al obtener a finales de 1986, en concurso público por oposición, la plaza de Profesor Titular de Universidad en el Departamento de Filosofía y Antropología Social de la Universidad de Santiago de Compostela. Y, a la par, por otro acontecimiento que iba a transfigurar su hacer y su talante investigador en el panorama de la Filosofía Medieval en España.

\section{De la filosofía medieval a la del Renacimiento del siglo XII}

2.1. I Congreso Nacional de Filosofia Medieval (Zaragoza, 12-14/12/1990): La fundación de la Sociedad de Filosofía Medieval (SOFIME) y Revista Española de Filosofía Medieval

Este acontecimiento iba a ser el I Congreso Nacional de Filosofía Medieval ${ }^{18}$, que se celebraba en Zaragoza del 12 al 14 de diciembre de 1990, y en el cual se fundaría la Sociedad de Filosofía Medieval (SOFIME) y que daría paso, también, a la creación de la Revista Española de Filosofía Medieval ${ }^{19}$, cuyo primer número, el $n^{\circ}$ 0, aparecía publicado en 1993. César L. Raña desde el primer momento y con total entrega fue uno de los más destacados participantes y colaboradores junto a Jorge M. Ayala. Con el mayor rigor académico y

12 Ágora: Papeles de Filosofia, 1 (1981), pp. 163-164.

13 Compostellanum: revista de la Archidiócesis de Santiago de Compostela, 30/1-2 (1985), pp. 141-165.

14 Azafea, 3 (1990), pp. 179-222.

15 Ágora: Papeles de Filosofia, 5 (1985), pp. 89-100.

16 Revista Española de Filosofia Medieval, 2 (1995), pp. 59-69.

17 Revista Española de Filosofia Medieval, 4 (1997), pp. 175-188.

18 Sociedad de Filosofia Medieval, Actas del I Congreso de Filosofia Medieval (coord. J.M. Ayala Martínez), Zaragoza, IberCaja Obra Cultural, 1992, 519 pp. Los títulos de los trabajos presentados se ofrecen en https://dialnet.unirioja.es/servlet/libro?codigo $=7043$.

19 Cf., página web de la Revista Española de Filosofia Medieval: https://www.uco.es/ucopress/ojs/ index. php/refime/issue/view/836 
generosidad siempre estuvo dispuesto colaborar con empeño ilusionado y decidido a hacer presente en todos los foros a la Filosofía Medieval.

De los siete Congresos organizados por la Sociedad de Filosofía Medieval (SOFIME), y celebrados hasta la fecha, ha participado de modo activo y con importantes contribuciones en seis de ellos. Ha sido en el I Congreso Nacional de Filosofía Medieval: Los límites de la razón en el pensamiento medieval, Zaragoza del 12 al 14 Diciembre de 1990; II Congreso Nacional de Filosofía Medieval: Ética y política en el pensamiento medieval ${ }^{20}$, Zaragoza del 15 al 16 Diciembre de 1994. III Congreso Nacional de Filosofía Medieval: Averroes y los averroísmos $^{21}$, Zaragoza del 17 al 18 Diciembre de 1998; IV Congreso Nacional de Filosofía Medieval: Maimónides y el pensamiento medieval², Córdoba del 9 al 11 Diciembre de 2004; $\mathrm{V}$ Congreso Internacional de Filosofía Medieval: El pensamiento político en la Edad Media $^{23}$, Alcalá de Henares del 11 al 13 Diciembre de 2008; VI Congreso Internacional de Filosofía Medieval: De natura ${ }^{24}$, Salamanca del 3 al 5 Diciembre de 2012. Y en el último, celebrado en Barcelona del 14 al 16 de Noviembre de 2016, VII Congreso Internacional de Filosofía Medieval: De relatione ${ }^{25}$, muy resentida ya su salud no pudo asistir.

Esto mismo iba a suceder con sus siempre esperadas colaboraciones en la Revista Española de Filosofia Medieval, que desde el primer número como uno de los promotores se hicieron presentes. Solamente no participó en seis ocasiones de los 25 números publicados ${ }^{26}$ de 1993 a 2017. Y su participación, mientras su salud le permitió viajar, iba a ser extensiva a

20 Sociedad de Filosofía Medieval, Actas del II Congreso de Filosofia Medieval, coord. J.M. Ayala Martínez), Zaragoza, IberCaja Obra Cultural, 1996, 542 pp.

https://dialnet.unirioja.es/servlet/libro?codigo $=342234$.

21 Averroes y los averroísmos: actas del III Congreso Medieval de Filosofia Medieval, coord. J.M. Ayala Martínez), Zaragoza, Prensas Universitarias de Zaragoza, 1999, 501 pp.

https://dialnet.unirioja.es/servlet/libro?codigo=7044.

22 Maimónides y el pensamiento medieval: VIII centenario de la muerte de Maimónides: actas del IV Congreso Nacional de filosofia medieval, Córdoba, 9, 10 y 11 de diciembre de 2004 (ed. J.L. Cantón Alonso), Córdoba, Servicio de Publicaciones, Universidad de Córdoba, 2007, XII+463 pp.

https://dialnet.unirioja.es/servlet/libro?codigo $=275451$.

23 El pensamiento político en la Edad Media, coord. P. Roche Arnas, Madrid, Fundación Ramón Areces, 2010, 729 pp., https://dialnet.unirioja.es/servlet/libro?codigo=428361.

24 De natura: la naturaleza en la Edad Media, J.L. Fuertes Herreros, Á. Poncela González (eds.), Ribeirão, Edições Húmus, 2015. 2 vols. (pp. 1-472 y 473-920). https://dialnet.unirioja.es/servlet/libro?codigo=654049.

25 Actas del VII Congreso Internacional de Filosofía Medieval: De relatione. Barcelona (UAB), 14-16 Noviembre 2016. «De relatione». EnraHonar. An International Journal of Theoretical and Practical Reason, M. Cabré Duran, A. Fidora (coords.), 61 (2018), pp. 1-138. https://revistes.uab.cat/enrahonar/issue/view/68/showToc. «Relation, Reason and Reality. Studies in Medieval Philosophy», EnraHonar. An International Journal of Theoretical and Practical Reason. M. Cabré Duran, A. Fidora, J. Mensa (coords.) Supplement Issue, 61 (2018), pp. 1-495.

https://ddd.uab.cat/pub/llibres/2018/enrahonar_a2018nsupissue/enrahonar_a2018nSupplissue.pdf.

26 Para una relación detallada, tal como se viene señalando, se pueden consultar la página web de la Revista Española de Filosofia Medieval, así como la base de datos Dialnet y en esta base de datos, también, entrando en César Lorenzo Raña Dafonte. 
los Congresos que la Société Internationale pour l'Étude de la Philosophie Médiévale celebró en Ottawa ${ }^{27}$, Canadá (1992), Erfurt ${ }^{28}$, Alemania (1997) y Porto ${ }^{29}$, Portugal (2002).

\subsection{César L. Raña y la filosofía del Renacimiento del siglo XII: una aproximación}

Esta dedicación de César L. a la filosofía del Renacimiento del siglo XII, de modo destacado, iba a quedar plasmada en la Revista Española de Filosofía Medieval. De entre las publicaciones realizadas cabría destacar las siguientes: «Ratio Lucerna: la razón como guía en el siglo XII ${ }^{30}$, «Clavis aurea: enseñanza y método en el siglo XII ${ }^{31}$, «Natura optima parens. La naturaleza en el siglo XII» $»^{32}$, y «Amistad y filosofía: A. de Rievaulx» ${ }^{33}$. En ellas quizá se encuentren algunas de las preocupaciones que están presentes en el pensamiento de César L. Raña y que sabe descubrir y actualizar en los grandes autores del Renacimiento del siglo XII: el papel y relevancia de la razón en el ser humano, la formación intelectual y la educación, la dimensión ética y vida virtuosa, las artes liberales, trívium y quadrivium, la naturaleza y la ciencia, y la amistad.

En la primera de dichas publicaciones, Ratio Lucerna, «pretende resaltar la gran importancia que se daba al cultivo de la razón en el siglo XII. Los principales representantes del pensamiento de ese siglo se pueden considerar, en parte al menos, como precedente de lo que será la Ilustración Europea. En efecto, su empeño por la racionalidad es notorio» ${ }^{34}$.

Y los autores que analizará serán Pedro Abelardo, Alano de Lille, Juan de Salisbury, Honorio de Autún, Guillermo de Conches, Hugo de San Víctor y esos apartados principales: Concepto de razón (ratio); la autoridad de la razón (ratio et auctoritas); la formación

27 IXe Congrès international de Philosophie Médiévale, Ottawa, du 17 au 22 août 1992. Les philosophies morales et politiques au Moyen Age / Moral and Political Philosophies in the Middle Ages. Actes du IXe Congrès international de Philosophie Médiévale, Ottawa, du 17 au 22 août 1992. Proceedings of the Ninth International Congress of Medieval Philosophy, Ottawa, 17 - 22 August 1992, Société Internationale pour l'Étude de la Philosophie Médiévale (S.I.E.P.M.), sous la direction de / edited by B.C. Bazán, E. Andújar, L.G. Sbrocchi, New York - Ottawa - Toronto, Legas, 1995, 3 vol.: I, 610 pp.; II, 611-1168 pp.; y III, 1169-1788 pp.

28 Was ist Philosophie im Mittelalter? Qu'est-ce que la philosophie au Moyen Age? What is Philosophy in the Middle Ages? Akten des X. Internationalen Kongresses für mittelalterliche Philosophie der Société Internationale pour l'Étude de la Philosophie Médiévale, 25. bis 30. August 1997 in Erfurt, herausgegeben von J.A. Aertsen und A. Speer. Für den Druck besorgt von A. Speer (Miscellanea Mediaevalia, 26). Berlin - New York, Walter de Gruyter, 1998, XXVI-1066 pp.

29 XIe Congrès International de Philosophie Médiévale de la Societé Internationale pour l'Étude de la Philosophie Mediévale (SIEPM). Porto, du 26 au 31 août 2002. M.C. Pacheco et J.F. Meirinhos (eds.), Intellect et imagination dans la Philosphie Médiévale / Intellect and Imagination in Medieval Philosphy / Intelecto e imaginação na Filosfia Medieval. Actes du XIe Congrès International de Philosophie Médiévale de la Societé Internationale pour l'Étude de la Philosophie Mediévale (SIEPM). Porto, 26-31 août 2002 (Rencontres de philosphie médievale, 11), Turnhout, Brepols Publishers, 2006, 3 vols. Raña Dafonte, C., Conocimiento y verdad en Juan de Salisbury, vol. II, pp.1053-1062.

30 Revista Española de Filosofia Medieval, 15 (2008), pp. 27-42. https://www.uco.es/ucopress/ojs/index. $\mathrm{php} /$ refime/issue/view/582.

31 Revista Española de Filosofia Medieval, 14 (2007), pp. 137-149. https://www.uco.es/ucopress/ojs/ind ex.p hp/refime/issue/view/585.

32 «Natura optima parens. La naturaleza en el siglo XII», Revista Española de Filosofia Medieval, 15 (2009), pp. 43-56. https://www.uco.es/ucopress/ojs/index.php/refime/issue/view/580.

33 Revista Española de Filosofia Medieval, 19 (2012), pp. 59-74.

34 Revista Española de Filosofia Medieval, 15 (2008), p. 27. 
intelectual y la educación; razón y religión; razón e investigación científica; y razón y naturaleza.

En la segunda, Clavis aurea, «pretende mostrar como el método se cultiva con esmero en las escuelas urbanas del siglo XII», fijándose «en magistri significativos de la época: Bernardo de Chartes, Pedro Abelardo, Hugo de San Víctor, Juan de Salisbury» ${ }^{35}$. Los apartados principales versan sobre el horizonte intelectual y cambios innovadores durante el siglo XII, el método de la enseñanza en el siglo XII y los elementos o momentos del método en el siglo XII, y que desde la perspectiva de las artes y saberes puede ser completado a través de Honorio de Autun $^{36}$.

En la tercera de las publicaciones, Natura optima parens, se propone mostrar «la novedad que se produce en el siglo XII en lo referente al concepto de naturaleza. Se contrapone a la visión simbólica de los siglos anteriores de la Alta Edad Media, en que era considerada la naturaleza como criatura y reflejo del Creador» ${ }^{37}$.

Tras ofrecer la visión medieval de naturaleza anterior al siglo XII, expondrá la nueva concepción que de la misma se ofrecerá en el Renacimiento del siglo XII. Mostrará como del simbolismo de la naturaleza progresivamente se irá pasando hacia el estudio racional de la misma, quedando dicho simbolismo en un segundo plano en este renaciente siglo. Se acentuará la consideración orgánica y autónoma de la misma, el estudio de sus causas, regida por leyes, y frente a la mera contemplación se insistirá en la necesidad del conocimiento experimental de la misma. Los autores principales donde quedará estudiada la naturaleza serán: Hugo de San Víctor, Juan de Salisbury y Alano de Lille.

Juan de Salisbury en su Entheticus de dogmate philosophorum. Juan de Salisbury, Entético sobre la doctrina de los filósofos, dirá a este respecto:

El conocimiento de la realidad mueve con fuerza a los filósofos agudos, para poder contemplar lo verdadero en su propia fuente.

La fuente de la verdad, la idea de bien, hace

que cada cosa sea lo que es, según la condición de su género.

De esta fuente brotan las causas de las cosas,

y todo responde a sus causas por la ley establecida.

La ley es la sucesión de las causas: la

naturaleza creada produce los efectos asimilándolos a las causas ${ }^{38}$.

35 Revista Española de Filosofia Medieval, 14 (2007), p. 137.

36 Magistrorum lectio. Un lección en el siglo XII» y «Honorio de Autún (1190?-1152): El exilio y la patria, o Sobre los las artes», Revista Española de Filosofia Medieval, 17 (2010), pp. 81-92 y 171-180. https:/www.uco.es/ucopress/ojs/index.php/refime/issue/view/578.

37 «Natura optima parens. La naturaleza en el siglo XII», Revista Española de Filosofia Medieval, 15 (2009), p. 43.

38 «Natura optima parens. La naturaleza en el siglo XII», Revista Española de Filosofia Medieval, 15 (2009), p. 53. Cesar efectuará la traducción del Entético sobre la doctrina de los filósofos, a la que me referiré más adelante. La cita que se ha hecho aquí aparece efectuada en dicha traducción, «Juan de Salisbury (110-1180): 
Y en la cuarta y última publicación, Amistad y Filosofía, César L., exponiendo al «doctor de la amistad», indicará que «este artículo se centra en el tema amistad y filosofía en el escritor del siglo XII, Aelred de Rievaulx. Para ello fue conveniente una alusión especial a Cicerón y al Cristianismo. También se hace mención de Platón, Aristóteles, San Jerónimo y San Agustín ${ }^{39}$, reparando y mostrando la relevancia e importancia que este tema tenía para la filosofía y para la propia vida del mundo medieval, y como en ésta deberían empeñarse los seres humanos en el presente:

El egoísmo y el altruismo son dos pulsiones naturales en todos los seres humanos. El primero es la raíz última de las aversiones y hostilidades, así como el segundo lo es de la simpatía y benevolencia. San Agustín, en su excepcional obra La ciudad de Dios, analiza con sutileza esas dos bases de la convivencia humana y, bajo el lema «dos amores han dado lugar a dos ciudades» (Fecerunt itaque civitates duas amores duo), hace ver cómo el devenir de la humanidad se debe en última instancia al egoísmo y al altruismo, siendo el primero la raíz de todos los males de la historia humana, así como el segundo es la raíz de todo lo bello y grandioso. En esta bifronte posibilidad está el fundamento de la amistad y el odio. La grandeza del ser humano está, principalmente, en que puede con su libre decisión y con su esfuerzo conseguir la parte positiva del dilema: la amistad. Tal vez sea la tarea más hermosa que pueden proponerse los seres humanos $y$, sin duda, la más gratificante ${ }^{40}$.

Se han señalado algunas de las publicaciones que César L. supo ofrecer en la Revista Española de Filosofía Medieval en este lúcido volcarse a la filosofía del Renacimiento en el siglo XII.

Pero faltan por destacar dos importantes, aunque breves, monografías dedicadas a Abe$\operatorname{lardo}^{41}(1079-1142)$ y a Juan de Salisbury ${ }^{42}$ (1110/20-1180). Fueron monografías, ajustadas con todo rigor a los requerimientos editoriales de la colección «Filósofos y Textos», que sabiamente dirigía Luis Jiménez Moreno, y que tanto eco han tenido y tienen en el ámbito de las aulas y bibliotecas universitarias.

En la primera de las monografías, César, de alguna manera se reconciliaba con Pedro Abelardo $^{43}$, al que en sus inicios había merecido su atención. Y ahora volvía para brindarle en apretadas páginas y textos lo mejor de su obra y pensamiento, destacando los apartados dedicados a la autoridad de la razón, las reglas de la investigación y de la interpretación de

Entético sobre la doctrina de los filósofos, $2^{\mathrm{a}}$ parte» Revista Española de Filosofia Medieval, 21 (2014), pp. 211, § 595-603. Más adelante se hará referencia también a dos bellos poemas de Alano de Lille traducidos por César.

39 Revista Española de Filosofia Medieval, 19 (2012), p. 59.

40 Ibidem. Lo resaltado en cursiva es mío. Quizás estas líneas muestran todo el valor y estima que sabía dar a la amistad, cultivándola con un cuidado siempre generoso.

41 Raña Dafonte, C., Abelardo (1079-1142), Madrid, Ediciones del Orto, 1998, 94 pp.

42 Raña Dafonte, C., Salisbury (1110/20-1180), Madrid, Ediciones del Orto, 1999, 94 pp.

43 «En torno a la ética de Pedro Abelardo», Revista Española de Filosofía Medieval, 3 (1983), pp. 203-210, y al que volverá: «La libertad en Pedro Abelardo», Revista Española de Filosofia Medieval, 11 (2004), pp. 67-82, así como en otros estudios que ya se han señalado, «Clavis aurea» (2007) y «Ratio lucerna» (2008). 
textos ${ }^{44}$; y los más principales de Pedro Abelardo como maestro de dialéctica y el problema de los universales ${ }^{45}$, así como el dedicado a la ética o filosofía moral ${ }^{46}$, que iban acompañados de sus correspondientes textos y bibliografía selecta ${ }^{47}$.

La segunda monografía, que trata sobre Juan de Salisbury, está dedicada «A Pili (mi mujer), a César y Pablo (nuestros hijos)». Será el autor que le abrirá a muchos de los tesoros que encierra la filosofía del renaciente siglo XII y que se encuentran también, compartiendo sus secretos, en otros autores. Expondrá en esta rica monografía el renacer cultural ${ }^{48}$ del siglo XII, trayendo ecos de aquella ponencia del Simposio de Santiago de Compostela (1985), El humanismo del siglo XII y su proyección en el humanismo, y que ahora cobraba seguridad y firmeza al redescubrir a Juan de Salisbury. Expondrá en apartados mayores el tema de las artes liberales $^{49}$, y que posteriormente descubrirá en otros autores como Alano de Lille o en Honorio Autún $^{50}$; y el de la filosofía ${ }^{51}$, exponiendo el problema del método, el conocimiento, la filosofía práctica o filosofía moral, y la política. Y cerrará la obra remitiendo a sus correspondientes textos y ofreciendo una selecta bibliografía ${ }^{52}$. A partir de este momento Juan de Salisbury se hacía presente como referente importante en la obra y pensamiento de César ${ }^{53}$, tal como ahora en el siguiente apartado, también, se verá.

\subsection{Bellos textos y hermosas traducciones de la filosofía del siglo XII}

Saber hacer atractiva la filosofía medieval en sus grandes temas fue una de las preocupaciones de César L. Su empeño le llevo en incesante búsqueda hasta dar con hermosos textos, sabiendo acercarlos a través de bellas traducciones.

En este sentido, en torno a la sabiduría y las artes liberales, del trivium y quadrivium, hay que destacar ese bello texto de Honorio de Autún, De animae exsilio et patria, De artibus. El exilio y la patria del alma, o Sobre las artes ${ }^{54}$. En cuyo capítulo primero se lee ${ }^{55}$ : «El exilio del hombre es la ignorancia, su patria es la sabiduría, a la que se llega por las artes liberales, como por otras tantas ciudades», para mostrar cómo estás conducen y llevan a la verdadera sabiduría: La gramática, retórica, dialéctica, aritmética, música, geometría, astronomía, física, mecánica y economía ${ }^{56}$. Y como «una vez cursadas las Artes Liberales se llega a la patria, o

44 Ibidem, pp. 16-22.

45 Ibid., pp. 23-41.

46 Ibid., pp. 41-56.

47 Ibid., pp. 57-94.

48 Raña Dafonte, C., Salisbury (1110/20-1180), pp. 12-20

49 Ibidem, pp. 20-3.

50 «Poema sobre la Encarnación del Verbo de Alano de Lille» (2012) y «Honorio de Autún (1190?-1152): El exilio y la patria del alma, o Sobre las artes» (2010), tal como a continuación se verá.

51 Raña Dafonte, C., Salisbury (1110/20-1180), pp. 30-52.

52 Ibidem, pp. 57.94. (2008).

53 Tal como se ha señalado en «Natura optima parens» (2009), «Clavis aurea» (2007) y «Ratio Lucerna»

54 «Honorio de Autún (1190?-1152): El exilio y la patria del alma, o Sobre las artes), Revista Española de Filosofia Medieval, 17 (2010), pp. 171-180, https://www.uco.es/ucopress/ojs/index.php/refime/issue/view/578.

55 Ibidem, p. 171.

56 Ibid., pp. 172-174. De la economía dirá: «La economía es la décima ciudad por la que nos acercamos a los atrios de la patria. Ella ordena los reinos y los honores, ella distingue los deberes y los rangos sociales. También 
verdadera sabiduría, que reluce en las Sagradas Escrituras, y que alcanza su perfección en la visión de Dios» ${ }^{57}$.

Así como el texto de Alano de Lille, Magistri Alani de Insulis de Incarnatione Christi rhythmus perelegans Quo divinum id opus omnes artium liberalum regulas aspernatum fuisse ingeniose cecinit. Un bello poema sobre la Encarnación de Cristo, de Alano de Lille (En el cual cantó con mucho ingenio cómo esta obra divina ha dejado en suspenso todas las reglas de la Artes Liberales $)^{58}$, en juego permanente y sutil de metáforas que culmina en la astronomía ${ }^{59}$.

Y no menos importante es el texto, Joannis Saresberiensis Entheticus de dogmate philosophorum. Juan de Salisbury, Entético sobre la doctrina de los filósofos ${ }^{60}$, en torno a la filosofía, así como la revisión de las tradiciones filosóficas que éste efectuará de la misma en este renaciente siglo XII. Se preguntará por la función de la filosofía ${ }^{61}$, por la verdad, por la razón humana. Revisará las distintas tradiciones y escuelas filosóficas, entre otras: estoicos, epicúreos, pitagóricos, académicos; y lo mismo hará con autores significativos, tales como Anaxágoras, Sócrates, Aristóteles ${ }^{62}$, Platón, Varrón, Cicerón, Séneca, Quintiliano ${ }^{63}$. Y reflexionará sobre la vida virtuosa y política, fundamentada en el amor, no en el cálculo e interés, «en todas partes ofrecen poca garantía las relaciones a precio» ${ }^{64}$, y alejada del temor.

$\mathrm{Al}$ igual que su reflexión sobre la vida práctica y teoría política en base a la concordia y ayuda mutua, alejada de la discordia y rebelión. Es el bello poema de Juan de Salisbury, Carmen de membris conspirantibus. Sobre la conspiración de los miembros corporales ${ }^{65}$, en el cual al final, tras intenso debate, los distintos miembros del cuerpo humano se ponen de acuerdo, ya que la comunidad, "res publica», es como un cuerpo en el que cada parte o miembros contribuye a la armonía y bienestar de todo el propio cuerpo:

Se ponen en acción, cumplen con sus deberes, y ejecutan su cometido,

enseña, a los que se apresuran hacia la patria, que los hombres se unen a los coros de los ángeles según el grado de sus méritos».

57 Ibid., p. 175.

58 «Poema sobre la Encarnación del Verbo de Alano de Lille», Revista Española de Filosofía Medieval, 19 (2012), pp. 187-190, https://www.uco.es/ucopress/ojs/index.php/refime/issue/view/574.

59 Ibidem, p. 189.

60 «Juan de Salisbury (110-1180): Entético sobre la doctrina de los filósofos, $1^{\text {a }}$ parte» Revista Española de Filosofia Medieval, 20 (2013), pp. 207-216, https://www.uco.es/ucopress/ojs/index.php/refime/issue/view/567. «Juan de Salisbury (110-1180): Entético sobre la doctrina de los filósofos, $2^{\text {a }}$ parte» Revista Española de Filosofia Medieval, 21 (2014), pp. 205-220, https:/www.uco.es/ucopress/ojs/index.php/refime/issue/view/561. «Juan de Salisbury (110-1180): Entético sobre la doctrina de los filósofos, $3^{\mathrm{a}}$ parte» Revista Española de Filosofia Medieval, 23 (2016), pp. 341-369, https://www.uco.es/ucopress/ojs/index.php/refime/issue/view/788.

61 «Juan de Salisbury (110-1180): Entético sobre la doctrina de los filósofos, $1^{\text {a }}$ parte», Revista Española de Filosofia Medieval, 20 (2013), p. 214: «¿Qué es la Filosofía? ¿Qué es la filosofía, a no ser fuente, camino, y guía de salvación, luz del alma, norma de vida, descanso feliz? Cierto que no vale para eliminar las inclinaciones, pero, con la actividad racional reprime y modera las dañinas».

62 «Juan de Salisbury (110-1180): Entético sobre la doctrina de los filósofos, $2^{\text {a }}$ parte», Revista Española de Filosofia Medieval, 21 (2014), pp. 207-218.

63 «Juan de Salisbury (110-1180): Entético sobre la doctrina de los filósofos, $3^{\text {a }}$ parte», Revista Española de Filosofia Medieval, 23 (2016), pp. 341-352.

64 Ibidem, p. 359, §1534.

65 «De membris conspirantibus. Razón y rebelión en el siglo XII», en El pensamiento político en la Edad Media (coord. P. Roche Arnas), Madrid, Fundación Ramón Areces, 2010, pp. 619-630. 
cada miembro vigila atento su propio trabajo.

A quienes la naturaleza hace compañeros en la vida,

el cuidado mutuo los hace compañeros de trabajo

y de superación de dificultades.

De este modo la concordia elimina el conflicto con un final feliz ${ }^{66}$.

Y sobre la vida cotidiana, en su dimensión ética y vida virtuosa, a través de los libros penitenciales, y que tantos frutos está dando en la investigación, ya que supone abrir la filosofía a una consideración mundana de la misma en el espacio compartido de la vida cotidiana al lado de la filosofía académica. En este sentido cabe destacar los distintos estudios y traducciones: «De vita non sancta en la Alta Edad Media» ${ }^{67}$; «Maestro Alano de Lille: libro penitencial o método para administrar y recibir dignamente el Sacramento de la Penitencia» ${ }^{68}$; SSito te ipsum. La responsabilidad individual y los penitenciales del siglo XII» ${ }^{69}$ y $«$ Cuestionario penitencial de principios del siglo $\mathrm{X} \gg{ }^{70}$.

Este acercarse, César L., a los grandes temas de la filosofía del siglo XII le llevaría a dar a conocer dos bellísimos poemas de Alano de Lille. Uno primero, Rhythmus, quo graphice natura hominis fluxa et caduca depingitur. Poema que de un modo vivo muestra la Naturaleza humana como fugaz y caduca ${ }^{71}$, en el cual se reflexiona sobre la naturaleza humana, sobre su fragilidad y condición finita, utilizando una metáfora de largo recorrido sapiencial y escriturístico, la rosa que como flor, que se marchita, nos representa:

[579A] Es un símbolo fidedigno

de nuestra vida, de nuestra muerte,

de nuestra condición, de nuestro destino.

Una rosa representa nuestra situación,

constituye una bella glosa de nuestra condición,

una lección de nuestra vida.

Ella florece con el alborear del día,

y con el crepúsculo vespertino

66 Ibidem, p. 627.

67 Revista Española de Filosofia Medieval, 12 (2005), pp. 191-204. https://www.uco.es/ucopress/ojs/ index.php/refime/issue/view/770.

68 Revista Española de Filosofia Medieval, 13 (2006), pp. 193-210. https://www.uco.es/ucopress/ojs/ index.php/refime/issue/view/588.

69 Revista Española de Filosofia Medieval, 18 (2011), pp. 60-80. https://www.uco.es/ucopress/ojs/ index.php/refime/issue/view/577.

70 Revista Española de Filosofia Medieval, 18 (2011), pp. 225-236. https://www.uco.es/ucopress/ojs/ index.php/refime/issue/view/577.

71 «Dos poemas del maestro Alano de Lille», Revista Española de Filosofia Medieval, 16 (2009), pp. 151154, https://www.uco.es/ucopress/ojs/index.php/refime/issue/view/580. Poemas que se complementan con el estudio ya señalado, «Natura optima parens. La naturaleza en el siglo XII», Revista Española de Filosofia Medieval, 16 (2009), pp. 43-56. 
la flor marchita resplandece ${ }^{72}$.

Y el otro poema que está dedicado a la naturaleza, Domus naturae. La casa de la naturaleza $a^{73}$, donde se ofrece una descripción muy bella de la misma en su hacer orgánico y autónomo, y siempre renaciente.

Existe un lugar separado de nuestra región por una larga distancia [490A], que se ríe de la cebada de nuestros campos.

Él solo puede cuanto pueden todos los demás...

No perece allí el encanto de la flor que nace,

muriendo al nacer: no es la rosa niña por la mañana,

y vieja decrépita al anochecer; sino que con rostro inmutable

se rejuvenece sin cesar con el don de la eterna primavera ${ }^{74}$.

\section{Conclusión}

Y así, cuando ya todo se ha hecho historia, concluye esta aproximación a la obra y pensamiento de César Lorenzo Raña Dafonte, medievalista lúcido, en recuerdo y memoria agradecida por sus contribuciones a la Filosofía Medieval, en especial en aquella en la que tanto destacó, disfruto y nos deleitó, la filosofía del Renacimiento del siglo XII.

$\mathrm{Y}$ se quiere hacer, trayendo aquella evocadora comparación que tanto gustaba recordar a César, viendo en él a ese gigante que con sencillez grande y corazón amigo, y siempre generoso, supo llevar a la Filosofía Medieval al punto alto en que está, al igual que la Sociedad de Filosofía Medieval (SOFIME) y a la Revista Española de Filosofía Medieval que ha sabido honrar su memoria:

Decía Bernardo carnotense que nosotros somos como enanos montados sobre los hombros de gigantes (nos ese quasi nanos gigantum umeris insidentes), para poder contemplar más cosas y más alejadas que los antiguos; pero no ciertamente por nuestra mayor agudeza visual, o por nuestra mayor estatura, sino porque somos llevados y elevados a lo alto con su gigantesca altura ${ }^{75}$.

Muchas gracias, César, medievalista lúcido, que tantos caminos supiste otear.

JOSÉ LUIS FUERTES HERREROS

Universidad de Salamanca

72 Ibidem, p. 151.

73 Ibid., pp. 154-157.

74 Ibid., p. 154.

75 Raña Dafonte, C., Salisbury (1110/20-1180), Madrid, Ediciones del Orto, 1999, p. 13 y «Clavis aurea: enseñanza y método en el siglo XII», Revista Española de Filosofia Medieval, 14 (2007), p. 139. La referencia, Juan de Salisbury, Metalogicon, III, 4; PL, 199, 900C. 